wersytetów. Promował 16 profesorów ${ }^{8}$. Jego seminarium biblijne we Lwowie miało charakter ekumeniczny, zanim w ogóle słowo to weszło w życie. Między jego uczniami byli nie tylko katoliccy księża, ale także żydowscy rabini i ormianie. Ks. Klawek nauczał nowych kierunków badań literackich nad Biblią, zanim jeszcze zostały one oficjalnie zaakceptowane przez Kościół Katolicki w trakcie Soboru Watykańskiego II. Miał niezwykły dar skupiania wokół siebie ludzi szukających rzetelnej wiedzy. Umiał wzbudzać ich predyspozycje badawcze. Był wzorem mistrza-nauczyciela. Choć czasem przytłaczał swą wiedzą i autorytetem swych ostatnich uczniów - (wśród których był także autor tych słów), zawsze był im szczerym i oddanym przyjacielem.

Kraków

ZDZISŁAW J. KAPERA

s Wg ustaleń ks. W. S mereki, art. cyt., s. 16.

Zdzisław J. Kapera

\title{
UZUPELNIENIA DO BIBLIOGRAFII PRAC KS. ALEKSEGO KLAWKA
}

Od momentu opublikowania „Bibliografii prac księdza Aleksego Klawka (1890-1969), profesora U.J.K. i U.J." na łamach Ruchu Biblijnego i Liturgicznego w r. 1970 upłynęło już 10 lat. W okresie tym starałem się notować wszystkie zaobserwowane luki w sporządzonym zestawieniu jak też z pomoca mgra Adama Konderaka z Biblioteki Uniwersyteckiej KUL prześledziłem streszczenie publikacji ks. A. Klawka na lamach "Internationale Zeitschriftenschau für Bibelwissenschaft und Grenzgebiete" (= IZBG), Düsseldorf oraz w ,New Testament Abstracts” (= NTA), Cambridge, Mass. Panu Konderakowi pragnę w tym miejscu serdecznie podziękować za rzeczową współpracę,

Poniższe zestawienie zawiera uzupełnienia do już opublikowanych numerów 1-318 publikacji ks. Klawka oraz szereg publikacji pośmiertnych. Zachowano pierwotny zestaw skrótów i opisów. Na oznaczenie streszczeń, abstraktów wprowadzono znak \%. Cytowane są jedynie obszerniejsze streszczenia obcojęzyczne. Wzmianki pominięto. Publikacje polskie zawierające streszczenia i wzmianki wyliczono na końcu, poza numeracją.

1935

76 a. O zadaniach Polskiego Towarzystwa Teologicznego, [Streszczenie referatu] w: Pamiętnik drugiego zjazdu naukowego $w$ Warszawie $w$ sierpniu 1933 roku, Warszawa 1935, Nakładem Polskiego Towarzystwa Teologicznego (= Nasza myśl teologiczna 2), ss. 8 i 19 [Dyskusja nad ref., por. s. 151].

\section{8}

Ad 82. Psałterz, Lwów 1938 -- Rec.: (Anonim), Psallite Sapienter, Biblioteka Religijna 7, 1938, nr 5, s. 1 [Por. też Ogłoszenie na s. 5]. 
Ad 173. \% [Hymnus der Anna, der Mutter Samuels], IZBG 4, 1955/56, H. 1/2, $\S 200$, s. 32 (M. Stenzel).

Ad 174. \%: Nowe „Miserere” (Psalm 50/51) - - IZBG 4, 1955/56, H. 1/2, $\S 333$, s. 53 (M. Stenzel).

1956

Ad 184. \%: [Biblische marianische Symbole], IZBG 5, 1956/7, H. 1/2, § 1636, s. 238 (J. Scharbert).

1961

Ad 188. Onomastyka biblijna - - Rec.: Zpravoday Místopisné Komise ČSAV (Praha) 1963, ss. 53-54 (V. Šmilauer).

1962

Ad 191. \%: [Das Lied von der Schöpfung: Gen 1, 1 - 2, 4], IZBG 10, 1963/4, § 243, s. 36 (J. Scharbert).

Ad 192. \%: Dominus regnavit (Ps 93 - Vulg. 92) - - IZBG 10, 1963/4, § 454, S. 65 (J. Scharbert).

Ad 193. \%: [Das Dekret des Apostolischen Stuhles über die Geschichtlichkeit der biblischen Bücher], IZBG 10, 1963/4, § 111, s. 16 (J. Scharbert).

1963

Ad 200.. \%: [Das Protoevangelium (Gen 3, 14-19], IZBG 11, 1964/5, § 255, s. 36 (J. Scharbert).

1964

Ad $211 \%$ : Najstarszy rękopis Ewangelii św. Mateusza - - NTA 9, 1964/5, $\S 140$, s. 39 (W. J. Pilch).

1966

Ad $257 \%$ : [Bibelstunde: Jesus lehrt in den Synagogen], IZBG 15, 1968/9, $\S 1256$, s. 176 (L. Stefaniak).

277 a. [Tłumaczenie:]

1967

Konstytucja Dogmatyczna o Objawieniu Bożym, ,Znak” 18, 1967, No. 152 (2), ss. $145-158$.

290 a. [Tłumaczenie:]

1969

Instrukcja Komisji Biblijnej w sprawie historyczności Ewangelii, w: J. K udasiewicz, red., Biblia Dzisiaj, Kraków 1969, Wyd. Znak, ss. 103-111.

1970

Ad 291 a. \%: [Der Hymnus der Engel Lk 2, 14], IZBG 18, 1971/2, § 767, s. 107 (E. Sitarz); NTA 15, 1970/1, § 545, s. 174 (J. Pilch).

322. [Odpowiedź na ankietę ,W sprawie sesji naukowej o doktrynalnych konsekwencjach Soboru" (Watykańskiego II). Obszerne fragmenty wypowiedzi cytowane w:] J. W. R osłon, Głosy biblistów polskich $w$ sprawie doktrynalnych konsekwencji Soboru Watykańskiego II. [Art. zamieszczony w pracy zbiorowej:] J. M y śk ó w red., Myśl posoborowa w Polsce, Warszawa 1970, ATK, ss. 306-330. Toż w wersji francuskiej: J. W. R osłon, Les biblistes polonais sur les consequences doctrinales du Concile Vatican II [w:] J. M yśków, éd., La Pensée postconciliare en Pologne, Varsovie 1970 , ATK, ss. 346-377. 
323. Refleksje na temat II Synodu Biskupów w Rzymie (11-27. X. 1969), „Apostolswo Chorych" 41, 1970, nr 1, s. 1-3.

324. Modlitwy Chrystusa wiszącego na Krzyżu, „Apostolstwo Chorych” 41, 1970 , nr 3, s. $1-2$.

325. Rozpowszechnianie Pisma Sw., „Apostolstwo Chorych” 41, 1970, nr 8, s. 4.

326. Psalm ufności i tęsknoty (129/130), „Apostolstwo Chorych" 41, 1970, nr 11 , ss. $3-5$.

Publikacje polskie zawierające streszczenia i omówienia prac ks. Klawka:

J. Frankowski, red., Polska bibliografia biblijna adnotowana za lata 1964-1968. Praca zbiorowa pod redakcją ks. J... F..., Warszawa 1971, ATK, $8^{\circ}$, ss. 296 [Wykaz 34 streszczeń, zob. indeks na s. 291, s. v. Klawek. Uwaga: nr 293 nie jest pióra ks. Klawka].

J. Fr a nk ow ski, red., Polska bibliografia biblijna adnotowana [w:] Polska bibliografia teologii $i$ prawa kanonicznego za rok 1969, Warszawa 1971, ATK, $8^{\circ}$, ss. $71-168$ [Por. nr 46. Zob. też nr 16 i 171 dotyczące ks. Klawka]. J. M yśków, B. Przy byszewski, red., Posoborowe publikacje teologiczne $w$ Polsce. Praca zbiorowa pod red. ks. J. M... i ks. B. P..., Warszawa 1969 , ATK, $8^{\circ}$, ss. 437.

[Odnośnie ks. Klawka por. ss. 21, $28 \mathrm{n}, 30,32,35,38,69-72,77,86-88$, $90 \mathrm{n}, 178,194,324,350 \mathrm{n}, 361 \mathrm{f}, 365,373$ i bibliografia na s. 400.]

J. M yśków, red., Publications théologiques postconciliares en Pologne. Ouvrage collectif. Rédacteur: J... M..., Varsovie 1970, Académie de Théologie Catholique, $8^{\circ}$, ss. 525.

[Odnośnie ks. Klawka, por. ss. 23, 30n, 35n, 39, 42, 79, 82, 88n, 100nn, 104n, 375 oraz bibliografia na s. 468].

Wspótczesna biblistyka polska 1945-1970. Osmy Kongres Biblistów Polskich. Praca zbiorowa pod red. ks. J. Eacha. II. Powojenna biblistyka polska. Praca zbiorowa pod redakcją ks. M. Wolniewicza, Warszawa 1972, Akademia Teologii Katolickiej, $8^{\circ}$, ss. 502.

[Por. ss. 16, 20, 176, 185, 205, 420-2, 249-51, 256, 261, 271n, 275, 279-283, $292,307 \mathrm{n}, 311 \mathrm{n}, 319,333 \mathrm{n}, 417,433,436,470,472]$.

M. Wolniewicz, red., Les sciences bibliques en Pologne après la guerre (1945-1970). Travail collectif sous la rédaction de l'abbé M... W..., Varsovie 1974, Académie de Théologie Catholique, $8^{\circ}$, ss. 300.

[Por. Ss. 8n, 19-22, 28, 34, 38, 47, 49, 51n, 56-60,62, 72n, 91n, 95-97, 123n, $238,242 \mathrm{n}, 280,282]$.

\title{
WYBÓR PUBLIKACJI O KS. ALEKSYM KLAWKU
}

\author{
(część II)
}

Niniejsze zestawienie jest kontynuacją ,Wyboru publikacji o Księdzu Profesorze Aleksym Klawku” zamieszczonym jako dodatek w „Bibliografii Prac Księdza Aleksego Klawka (1890-1969), Profesora U.J.K. i U.J." na łamach „Ruchu Biblijnego i Liturgicznego" 23, 1970, ss. 335-336. Nawiązano do pierwotnej numeracji, z tym, że $\mathrm{nr} 21$ (w wersji poprawionej) umieszczono ponownie pod $\mathrm{nr} 60$. Uznano za celowe zamieszczenie w bibliografii kilku prac magisterskich i licencjackich. Podano także kilka artykułów znajdujących się aktualnie w druku. 
21. [Zbiorowe] Ks. Aleksy Klawek (1890-1969). Wspomnienia przyjaciót, kolegów $i$ uczniów. Z teki pośmiertnej. Bibliografia, numer specjalny „Ruchu Biblijnego i Liturgicznego” 23, 1970, $\mathrm{Nr} 6$, ss. 257-336, 1 fot.

22. [Zbiorowe] „Analecta Cracoviensia” III, 1971, [Kraków 1971, Polskie Towarzystwo Teologiczne, $8^{\circ}$, ss. 452,2 fot. Numer specjalny poświęcony pamięci ks. prof. A. Klawka i ks. prof. T. Dlugosza. Zawiera nr 44].

23. [Zbiorowe] „Folia Orientalia” XXI, 1980 [Obj. 17 ark., w druku]. [Księga ku uczczeniu 10 rocznicy śmierci ks. prof. A. Klawka. Oprócz nr 31 i 40 zawiera 25 artykułów uczonych polskich i zagranicznych].

24. Kazimierz BRYLINSKI, Wkład Księdza Profesora Doktora Aleksego Klawka w rozwój biblistyki w latach 1945-1969, Wrocław 1973, Papieski Wydział Teologiczny, maszynopis, ss. 77 (praca magisterska wykonana na seminarium Nowego Testamentu pod kierunkiem ks. dr Z. Kaznowskiego przy współudziale ks. dra St. Pisarka).

25. Ks. Jerzy CHMIEL, Mentalność biblisty, RBL 23, 1970, ss. 297-301.

26. Ks. Feliks GRYGLEWICZ, Badania ks. prof. A. Klawka nad Nowym Testamentem, RBL 23, 1970, ss. 276-279.

27. Ks. Stanisław GRZYBEK, Sp. ks. prof. Aleksy Klawek (1890-1969), RBL 23, 1970, ss. 259-266.

28. Ks. Stanisław GRZYBEK, „Czas, abym odszedt...” Przemówienie na pogrzebie śp. ks. A. Klawka $w$ dniu 25 listopada 1969 r., wygłoszone $w$ kościele akademickim św. Anny w Krakowie, RBL 23, 1970, ss. 302-305.

29. Zdzisław J. KAPERA, Bibliografia prac księdza Aleksego Klawka (1890-1969), profesora U.J.K. i U.J., RBL 23, 1970, ss. 319-336. [Wylicza 321 pozycji. Zawiera indeks rzeczowy i dodatek ,Wybor publikacji o Księdzu Profesorze Aleksym Klawku", na ss. 334 -336].

30. Zdzisław J. KAPERA, Uzupetnienia do bibliografii prac księdza Aleksego Klawka, RBL 33, 1980 (Obj. 0,2 ark. Zawiera uzupełnienia do nr 1 -321 oraz nowe $\mathrm{nr} 76 \mathrm{a}, 277 \mathrm{a}, 290 \mathrm{a}, 322-326)$.

31. Zdzisław J. KAPERA, A curriculum vitae of Rev. Aleksy Klawek (1890-1969), „Folia Orientalia” 21, 1980 (w druku, obj. 0,35 ark.).

32. Zdzisław J. KAPERA, Curriculum vitae ks. prof. A. Klawka, RBL 33, 1980 (obj. 0,45 ark. Uzupelniona i poprawiona wersja polska $\mathrm{nr} 31$ ). 33. Zdzisław J. KAPERA, O pełniejsza ocenę dorobku onomastycznego ks. prof. Aleksego Klawka, RBL 33, 1980 (obj. 0,5 ark.).

34. Tadeusz LEWICKI, Z dziejów orientalistyki lwowskiej, RBL 33, 1980 (obj. 0,25 ark.).

35. Ks. Stanisław 乇ACH, Wspótczesna biblistyka polska, „Znak” 24, 1972, nr 10 (220), ss. 1373-1391 [Por. ss. 1374n i 1379n].

36. Ks. Wojciech PAZERA, Ks. Aleksy Klawek jako komentator psalmów, Kraków 1978, Papieski Wydział Teologiczny, maszynopis, ss. 88 (Praca licencjacka pisana pod kierunkiem ks. prof. dra Stanisława Grzybka).

37. Ks. Michał PETER, Sp. ks. Aleksy Klawek, "Miesięcznik Kościelny Archidiecezji Poznańskiej"' 21, 1970, nr 9, ss. 212-214.

38. Ks. Michał PETER, Człowiek Uniwersytetu (Aleksy Klawek 18901969), [w:] Byli wśród nas, Praca zbiorowa pod red. Feliksa Lenorta, Poznań 1978, Księgarnia św. Wojciecha, ss. 349-356, 1 fot.

39. Ks. Michał PETER, Ks. Profesor Aleksy Klawek (1890-1969). Próba charakterystyki jego metody naukowej, Poznań 1979, maszynopis, ss. 10. [Por. niżej].

40. Ks. Michal PETER, The Reverend Professor Aleksy Klawek (18901969). A characterization of his scientific method, „Folia Orientalia" 21, 1980 (w druku, obj. 0,6 ark. wersja angielska $\mathrm{nr} 39$ ). 
41. Stefan PIECZARA, Ks. Aleksy Klawek, (11. V. 1890 - 22. XI. 1969) wybitny uczony, filolog, lingwista $i$ humanista polski, Sprawozdania Poznańskiego Towarzystwa Przyjaciół Nauk za I i II kwartał 1970 r., nr 1 (ogólnego zbioru $\mathrm{nr} 84$ ), ss. 214-216.

42. Urszula PEOSZYÑSKA-PRZEKLAS, Ks. Aleksy Klawek na tle rozwoju ruchu biblijnego $w$ Polsce, Lublin 1975, Katolicki Uniwersytet Lubelski, maszynopis, ss. 70 (praca magisterska wykonana pod kierunkiem ks. prof. dra hab. L. Stachowiaka).

43. Ks. Władysław SMEREKA, Ks. prof. Aleksy Klawek jako wykladowca i komentator psalmów (ze wspomnień ucznia), RBL 23, 1970, ss. $279-291$.

44. Ks. Władysław SMEREKA, Wybitny polski biblista - ks. Aleksy Klawek, „Analecta Cracoviensia” 3, 1971, ss. 7-19, 1 fot. [Résumé, ss. 18-19].

45. Ks. Władysław SMEREKA, Ks. prof. Aleksy Klawek, ,Tygodnik Powszechny" 26, 1972, nr 1 (1197), s. 3, 1 fot.

46. Ks. Władysław SMEREKA, Wielkopolska czci pamięć dwóch wybitnych biblistów, „Tygodnik Powszechny” 1973, nr 21, s. 7.

47. Ks. Władysław SMEREKA, Polskie Towarzystwo Teologiczne $w$ hotdzie błog. królowej Jadwidze, RBL 31, 1978, ss. 326-329.

48. Ks. Władysław SMEREKA, Tablica pamiatkowa ku czci śp. ks. prof. Klawka (obj. 0,25 ark. Ukaże się w wersji ang. na lamach „Folia Orientalia" 22, 1981).

49. Ks. Piotr STACH, Podróż naukowa do Ziemi Swiętej zorganizowana przez Polskie Towarzystwo Teologiczne we Lwowie, Lwów 1936, publ. 1937, Nakładem Autora, $8^{\circ}$, ss. 495, 87 fot., 1 mapka.

[Odnośnie ks. Klawka, por. ss. 9, 13, 16, 20, 21, 22, 28, 31n, 34n, 37, 71, 73, $89,103,164,173,194,301,348,369,425 n, 441$, oraz fot. $1,32,83$ ? Nota bene: fot. 32: Oddanie holdu O. M.-J. Lagrange'owi].

50. Ks. Lech STACHOWIAK, Katolicka biblistyka polska w latach 1900-1945, [w:] B. Bejze, red., W kierunku chrześcijańskiej kultury, Warszawa 1978, Akademia Teologii Katolickiej, ss. 551-567 [Por. ss. 561-563].

51. Ks. Lech STACHOWIAK, Ks. Aleksy Klawek jako egzegeta i tiumacz Biblii, Sprawozdania Oddz. Krakowskiego PAN, II półrocze $1979 \mathrm{r}$. (w druku, obj. 0,15 ark.).

52. Ks. Lech STACHOWIAK, Ks. Aleksy Klawek jako egzegeta $i$ thumacz Biblii, RBL 33, 1980 (pełna wersja nr 51. Obj. 0,8 ark.).

53. [Ks. Jan SZURLEJ?], „Którzy Mnie objaśniaja posiąda żywot wieczny" (Syr 24, 34), „Apostolstwo Chorych" 41, 1970, nr 11, ss. 1-3, 1 fot.

54. Witold TASZYCKI, Ks. Aleksy Klawek jako onomasta, RBL 23, 1970, ss. $291-293$.

55. Witold TASZYCKI, Ks. Aleksy Klawek jako onomasta (1890-1969), „Onomastica" 17, 1972, ss. 304-306, 1 fot. [Przedruk nr 54].

56. Ks. Marian WOLNIEWICZ, Biblijna działalność ks. prof. Klawka $w$ Wielkopolsce (1917-1923), RBL 23, 1970, ss. 266-276.

57. Ks. Marian WOLNIEWICZ, Wielkopolskie lata ks. profesora Klawka, „Przewodnik Katolicki” 76, 1970, nr 50, ss. 470-471, 2 fot.

58. Ks. Marian WOLNIEWICZ, Studium Pisma Siwiętego w Arcybiskupim Seminarium Duchownym w Poznaniu w latach 1835-1939, Poznań 1969, Księgarnia św. Wojciecha, 8०, ss. 103 (= Sprawy biblijne XXII). [Odnośnie ks. Klawka por. ss. 41n, 46, 51, 55, 57, 58-61, 71n, 74, 76, 81, 88-91, 101 oraz bibliografia na s. 88].

59. Andrzej ZABORSKI, Filolog i nauczyciel, RBL 23, 1970, ss. 293-297. 
60. Andrzej ZABORSKI, Prof. dr Aleksy Klawek (1890-1969), „Przegląd Orientalistyczny" 1971, $\mathrm{nr} 2$ (78), s. 209-210.

61. Andrzej ZABORSKI, Rev. Prof. Dr. Aleksy Klawek (1890-1969), „Folia Orientalia” 13, 1971 (publ. 1972), ss. 5-7, i fot.

62. Włodzimierz ZAJĄCZKOWSKI, Działalność ks. prof. Aleksego Klawka $w$ Polskim Towarzystwie Orientalistycznym $i$ Komisjach Orientalistycznych Polskiej Akademii Umiejętności i Krakowskiego Oddziału Polskiej Akademii Nauk, Sprawozdania Oddz. Krakowskiego PAN, II półrocze 1979 (w druku, obj. 0,05 ark.).

Kraków

ZDZISEAW J. KAPERA

\section{UWAGA PRENUMERATORZY}

W związku ze wzrostem kosztów druku uprzejmie informujemy Szanownych Prenumeratorów, iż $z$ dniem 1 I 1981 r. wysokość prenumeraty rocznej wynosić będzie $180 \mathrm{zl}$, półrocznej - 90 zł.

Cena pojedynczego zeszytu wynosić będzie 30 zl. 